\title{
Selective localization of $\gamma$-enolase in stromal cells of cerebellar hemangioblastomas
}

\author{
J. A. Feldenzer ${ }^{1}$ and P. E. McKeever ${ }^{2}$ \\ 1 Department of Surgery, Section of Neurosurgery, and \\ 2 Department of Pathology, Section of Neuropathology, Taubman Health Care Center, \\ University of Michigan, 1500 E. Medical Center Drive, Ann Arbor, MI 48109, USA
}

\begin{abstract}
Summary. Three cases of cerebellar hemangioblastoma were studied using the immunoperoxidase technique to localize $\gamma$-enolase, also known as neuronspecific enolase. The stromal cells demonstrated positive staining for $\gamma$-enolase, while endothelial cells and pericytes showed no reactivity. Two vascular lesions, an angiosarcoma and a cutaneous angioma, were studied and found to be nonreactive for $\gamma$-enolase. All tumors were also tested for factor VIII/von Willebrand factor, glial fibrillary acidic protein, and the S-100 protein. The lack of expression of $\gamma$-enolase in endothelial cells of hemangioblastomas demonstrates a clear antigenic distinction from neighboring $\gamma$-enolase-positive stromal cells. The significance of this finding and its implications for stromal cell histogenesis are discussed.
\end{abstract}

Key words: Cerebellar hemangioblastoma $-\gamma$-enolase - Immunohistochemistry - Neuron-specific enolase - Stromal cell

The cerebellar hemangioblastoma is a benign vascular neoplasm found alone or as part of the von HippelLindau disease complex $[15,16,28,30]$. Light microscope and ultrastructural studies of this tumor have established the presence of two characteristic cell types: endothelial cells and stromal cells. Pericytes have also been found $[4-6,11,20,35]$. The lipidcontaining stromal cells are unlike other normal or pathological cell types and their histogenesis remains unresolved $[5,26,29,30]$.

Ultrastructural and tissue culture studies have generally supported the hypothesis that stromal cells

Offprint requests to: J. A. Feldenzer (address see above) originate from angiogenic mesenchyme or tumor endothelial cells. Several factors do not support this concept. Transitional cells have not been demonstrated ultrastructurally, and Spence and Rubinstein were unable to show interconvertibility between endothelial and stromal cells in tissue culture [35]. Alternatively, it has been suggested that stromal cells are derived from tumor endothelial cells [2] or from fibrous astrocytes that progressively accumulate lipid [14].

Immunohistochemical studies using glial fibrillary acidic protein (GFAP) and factor VIII/von Willebrand factor (FVIII/vWF) have added to the controversy. Kepes et al. conclude that the presence of GFAP in some stromal cells suggests that they are "lipidized astrocytes" [21]. Deck and Rubinstein contend that the presence of GFAP in a cell does not define a glial cell and that stromal cells are capable of taking up extracellular GFAP from neighboring reactive astrocytes [8]. Jurco et al. reported that FVIII/vWF, a specific endothelial cell marker, stained stromal cells positively in all sixteen hemangioblastomas studied [18]. However, McComb et al. detected no positive staining of stromal cells and emphasized the antigenic distinction of stromal and endothelial cells [25].

Enolases are a group of glycolytic enzymes in which three immunologically distinct subunits, $\alpha, \beta$, and $\gamma$, have been characterized. The $\gamma$ subunit has been detected in high concentrations in both central and peripheral nervous tissue as $\alpha \gamma$ - and $\gamma \gamma$-enolases [32]. The $\gamma \gamma$-enolase is homologous to the nervous systemspecific protein previously known as 14-3-2 [3]. Initial histochemical studies demonstrated the presence of $\gamma$ enolase in neurons and neuroendocrine (APUD system) cells $[1,19,33]$. It has also been detected in other tissues [10, 19].

In this study, the expression of $\gamma$-enolase was examined in three cases of cerebellar hemangioblastoma and two lesions known to arise from angiogenic precursors: an angiosarcoma and a cutaneous angioma. 
Table 1. Clinical and pathological data

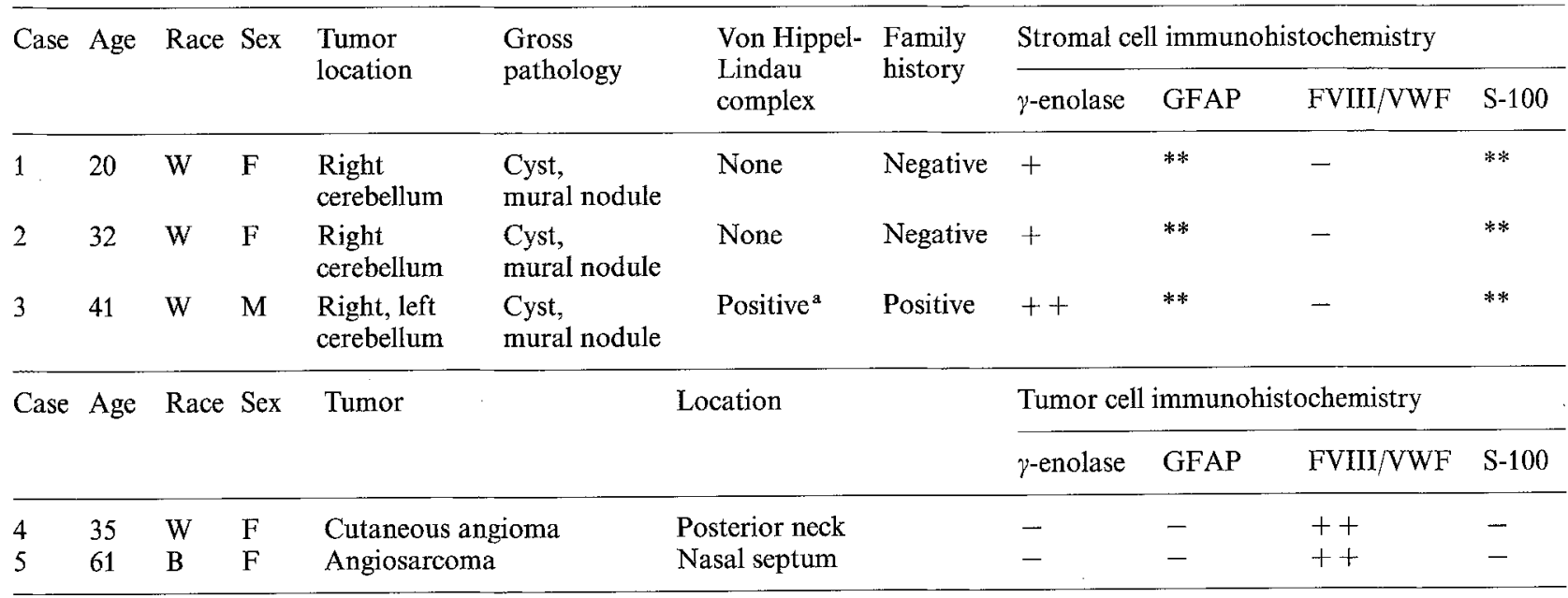

a Angiomatosis retinae, renal cell carcinoma

- : Negative staining; + : positive staining; ++ : strongly positive staining; ${ }^{*}$ : focally positive staining; GFAP: Glial fibrillary acidic protein; FVIII/VWF: factor VIII/von Willebrand factor

\section{Materials and methods}

Tissue was prepared from paraffin-embedded blocks and standard hematoxylin-eosin (H\&E) staining was performed. Immunostaining was done using the avidin-biotin system [12]. Sections were deparaffinized, treated with $10 \% \mathrm{H}_{2} \mathrm{O}_{2}$ in methanol followed by a phosphate-buffered saline (PBS) wash and then treated with normal goat serum. Antisera (Dako, Santa Barbara, CA, USA) against $\gamma$-enolase, GFAP, FVIII/vWF and S-100 protein and tissue were incubated and washed in PBS. Biotinlabeled goat anti-rabbit immunoglobulin was incubated with tissue, washed in PBS and then incubated with avidin-biotin peroxidase complex (Vector, Buringame, CA, USA). Tissues were then washed and sections developed in diaminobenzidine: $\mathrm{H}_{2} \mathrm{O}_{2}$ (Sigma, St. Louis, MO, USA). Tissues were counterstained with hematoxylin [23]. In one case (case 3, see Table 1), tumor tissue was minced into $1-2 \mathrm{~mm}^{3}$ fragments and fixed in formaldehyde $(3 \%)$-glutaraldehyde $(3 \%)$ with $0.1 \mathrm{M}$ cacodylate buffer. Sections were postfixed, dehydrated and then embedded in Epon. Uranyl acetate (2\%) was used for en bloc staining. Tíssue was sectioned on a Sorval ultramicrotome (MT-2), stained with Raynaud's lead citrate and examined on a Zeiss 109 electron microscope.

\section{Results}

Clinical and pathological data are summarized in Table 1. Operative findings revealed cystic cerebellar tumors with associated mural nodules in each case.

H\&E-stained sections demonstrated large stromal cells containing foamy cytoplasm separated by the endothelial cells of multiple thin-walled vessels. The stromal cells of all three hemangioblastomas were positive for $\gamma$-enolase (NSE) while endothelial cells were nonreactive (Figs. 1, 2). The $\gamma$-enolase reactivity was independent of the relative predominance of the endothelial (reticular variant) versus stromal cell (cellular variant) components of each hemangioblas- toma. FVIII/vWF stained the endothelial cells but stromal cell reactivity was not observed (Fig. 3). GFAP-positive cells, detected in each hemangioblastoma, were infrequent and mainly localized to the periphery of the tumor. The S-100 protein was detected in a few cells of each hemangioblastoma, although uniform staining could not be demonstrated. An ultrastructural study of one case revealed the two major cell types, but Weibel-Palade bodies could not be identified in either endothelial or stromal cells.

Two vascular tumors were studied with $H \& E$ and immunohistochemical methods. A cutaneous angioma demonstrated reactivity to FVIII/vWF but was nonreactive for $\gamma$-enolase, GFAP and S-100 protein. Similarly, the malignant cells of an angiosarcoma showed no staining with $\gamma$-enolase, GFAP or S-100 protein while FVIII/vWF staining was positive.

\section{Discussion}

Stromal cell histogenesis has been debated since the original descriptions of the tumor by Lindau in 1926 and Cushing and Bailey in 1928 [7, 22]. Immunohistochemical studies have not established a mesodermal or neuroectodermal origin. GFAP-positive stromal cells have been suggested to arise from the uptake of extracellular lipid by "trapped astrocytes" $[14,21]$. This suggestion is consistent with a fraction of stromal cells positive for S-100 [36], since astrocytes contain S-100 protein. Others have proposed that stromal cells acquire extracellular GFAP from nearby "reactive astrocytes" [8].

The use of FVIII/vWF $[13,24]$ has not clarified the issue. The data of Jurco et al. [18] are in direct 


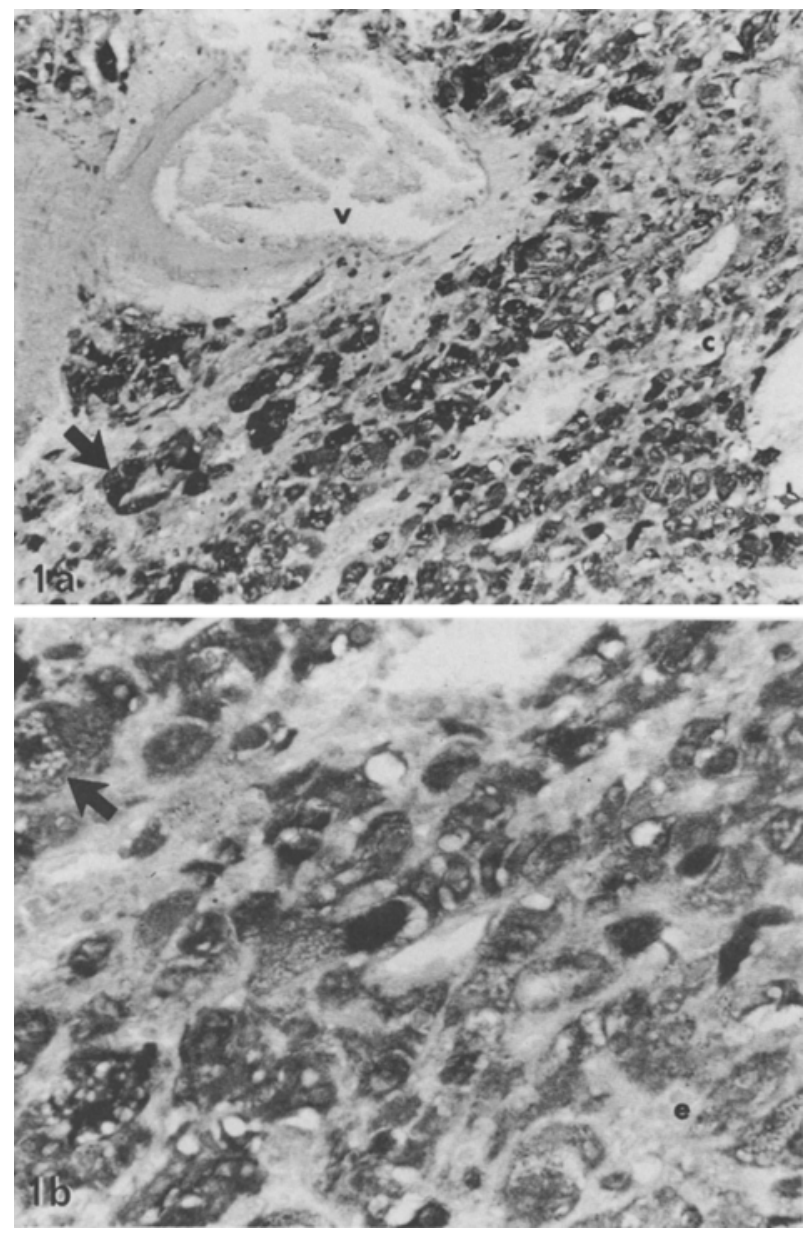

Fig. 1. a Stromal cells (arrow) of this hemangioblastoma immunostain for $\gamma$-enolase. In contrast, capillaries (c) are negative. A larger vessel (v) shows no reactivity with anti- $\gamma$-enolase. Immunoperoxidase avidin-biotin conjugate $(A B C)$ stain for $y$ enolase, $\times 114$. $b$ Higher magnification of lower middle portion of a shows $\gamma$-enolase-positive stromal cells and negative endothelial cells (e). Clear round vacuoles in stromal cells (arrow) represent extracted lipid. Immunoperoxidase $\mathrm{ABC}$ stain for $\gamma$ enolase, $\times 291$

conflict with those of McComb et al. [25]. These results and those of Jellinger and Denk on blood group isoantigens [17] indicate a clear antigenic distinction between stromal and endothelial cells. Ho's ultrastructural data on the presence of Weibel-Palade bodies in both stromal and endothelial cells support an angiogenic mesenchymal origin for stromal cells [11]. Ho suggests that FVIII/vWF staining of stromal cells is related to the presence of Weibel-Palade bodies which have been shown to contain von Willebrand protein [38]. He indicates that the lack of expression of FVIII/vWF in stromal cells demonstrated by McComb et al. was due to an insufficient number of Weibel-Palade bodies or their structural alteration with subsequent antigenic loss.
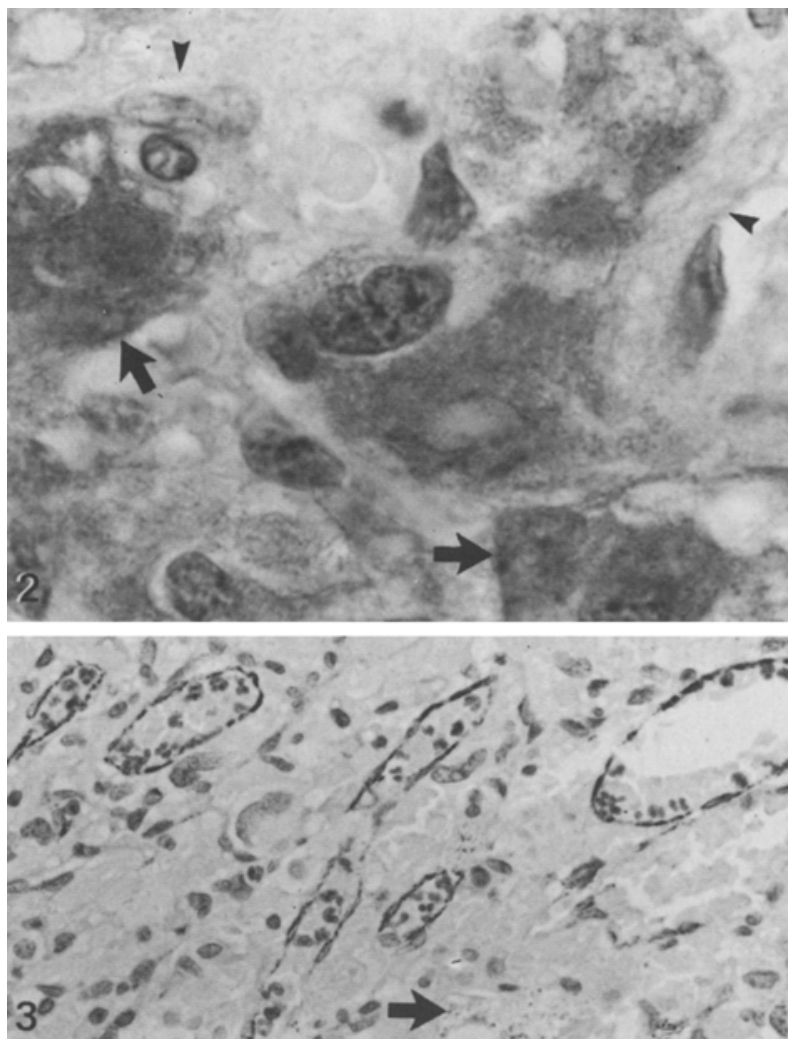

Fig. 2. Close up of stromal (arrows) and capillary endothelial cells (arrowheads) counterstained for nuclei. Immunoperoxidase $\mathrm{ABC}$ stain for $\gamma$-enolase and hematoxylin, $\times 1220$

Fig. 3. Stromal cells of hemangioblastoma do not immunostain for factor VIII/von Willebrand factor (FVIII/VWF). Dark granules in the cytoplasm of a few stromal cells (arrow) are lipochrome. In contrast, endothelial cells are positive. Immunoperoxidase $\mathrm{ABC}$ stain for FVIII/VWF and hematoxylin, $\times 310$

Our immunohistochemical study also demonstrates a clear antigenic distinction between stromal and endothelial cells regarding FVIII/vWF expression. Our data support those of McComb et al. In one case studied ultrastructurally, Weibel-Palade bodies could not be identified in endothelial or stromal cells. This negative result does not refute Ho's contention that stromal cell staining with FVIII/vWF may be related to the presence and concentration of WeibelPalade bodies.

The stromal cells in each case expressed $\gamma$-enolase, while endothelial tumor cells were nonreactive. $\gamma$-Enolase staining of these two cell types has not been previously reported in hemangioblastomas and offers further evidence of their antigenic distinction. In addition, an angiosarcoma and cutaneous angioma, both known to arise from angiogenic precursors, were nonreactive for $\gamma$-enolase.

$\gamma$-Enolase (NSE) is present in high concentrations in the central and peripheral nervous systems and 
in neuroendocrine cells (APUD system) [1, 19, 33]. Reactive astrocytes and several central nervous system tumors focally stain positive for $\gamma$-enolase $[9,37]$. Schmechel et al. have shown that neurons switch from non-neuronal enolase $(\alpha \alpha)$ to neuron-specific enolase $(\gamma \gamma)$ in developing rat and rhesus monkey brains [34]. This switch is closely correlated to the differentiated state and occurs in neurons of cerebellum and neocortex. The presence of $y$-enolase in stromal cells may reflect a derivation from neuronal, astrocytic or neuroendocrine precursors. However, the "presence" of immunoreactive $\gamma$-enolase as a specific marker has been questioned $[27,31]$. It has been suggested that quantitative measurement in addition to localization will provide the most useful information regarding its significance [31].

Kato et al. detected $\gamma$-enolase in other human organ systems using a sensitive enzyme immunoassay method [19]. Haimoto et al. localized $\gamma$-enolase in a variety of human tissues [10]. Although $\gamma$-enolase was demonstrated in the smooth muscle cells of the media of the aorta and of the afferent arteries of the juxtaglomerular apparatus, vascular endothelial cells were nonreactive. Recently, Pahlman et al. detected $\gamma$-enolase in neuroendocrine and nonneuroendocrine tumor specimens and derived cell lines by enzymatic methods and radioimmunoassay [27]. They conclude that $\gamma$-enolase is not exclusively expressed in neuroendocrine tumor cells. The variety of sites in which $\gamma$-enolase has been found underscores the significant absence of $\gamma$-enolase in endothelial cells contrasted with its presence in stromal cells. Thus, $\gamma$ enolase provides additional new evidence of the difference between these cellular populations.

However, because $\gamma$-enolase expression is not specifically restricted to neurons or neuroendocrine cells, but is also found in normal tissues and nonneuroendocrine tumor cells, its significance regarding stromal cell histogenesis must be questioned. The presence or absence of $\gamma$-enolase may simply reflect the present metabolic needs of the cell type without relation to its line derivation. Nevertheless, this study has clearly demonstrated another antigenic distinction between stromal and endothelial cells of hemangioblastomas. Any hypothesis suggesting stromal cell derivation from endothelial tumor cells should account for this fact.

Acknowledgements. We thank Dr. Ricardo V. Lloyd for immunostaining and reviewing the manuscript. Mr. Craig Biddle and Mr. Edward Burke provided photographic assistance. Ms Cassandra Richardson and Ms Sue Neely typed the manuscript.

\section{References}

1. Asa SL, Ryan N, Kovacs K, Singer W, Marangos PJ (1984) Immunohistochemical localization of neuron-specific enolase in the human hypophysis and pituitary adenomas. Arch Pathol Lab Med 108:40-43

2. Bailey O, Ford R (1942) Sclerosing hemangiomas of the central nervous system: progressive tissue changes in hemangioblastomas of the brain and in so-called angioblastic meningiomas. Am J Pathol 18:1-27

3. Bock E, Dissing J (1975) Demonstration of enolase activity connected to the brain-specific protein 14-3-2. Scand J Immunol [Suppl 2] 4:31-36

4. Cancilla PA, Zimmerman HM (1965) The fine structure of cerebellar hemangioblastoma. J Neuropathol Exp Neurol $24: 621-628$

5. Castaigne P, David M, Pertuiset B, Escourolle R, Poirier J (1968) L'ultrastructure des hemangioblastomes du systeme nerveux central. Rev Neurol (Paris) $118: 5-26$

6. Chaudry AP, Montes M, Cohn GA (1978) Ultrastructure of cerebellar hemangioblastoma. Cancer $42: 1834-1850$

7. Cushing H, Bailey $\mathbf{P}$ (1928) Tumors arising from the blood vessels of the brain: angiomatous malformations and hemangioblastomas. Charles C. Thomas, Springfield, pp 105203

8. Deck JHN, Rubinstein LJ (1981) Glial fibrillary acidic protein in stromal cells of some capillary hemangioblastomas: significance and possible implications of an immunoperoxidase study. Acta Neuropathol (Berl) 54:173-181

9. Haglid K, Carlsson CA, Stavrou D (1973) An immunological study of human brain tumors concerning the brainspecific proteins S-100 and 14.3.2. Acta Neuropathol (Berl) $24: 187-196$

10. Haimoto H, Takahashi Y, Koshikawa T, Nagura H, Kato $\mathrm{K}$ (1985) Immunohistochemical localization of $\gamma$-enolase in normal human tissues other than nervous and neuroendocrine tissues. Lab Invest 52:257-263

11. Ho KL (1984) Ultrastructure of cerebellar capillary hemangioblastoma. I. Weibel-Palade bodies and stromal cell histogenesis. J Neuropathol Exp Neurol 43:592-608

12. Hsu SM, Raine L, Fanger H (1981) A comparative study of the peroxidase-antiperoxidase method and an avidin-biotin complex method for studying polypeptide hormones with radioimmunoassay antibodies. Am J Clin Pathol 75:732738

13. Jaffe EA (1977) Endothelial cells and the biology of Factor VIII. N Engl J Med 296:377-383

14. Jakobiec FA, Font RL, Johnson FB (1976) Angiomatosis retinae: a ultrastructural study and lipid analysis. Cancer $38: 2042-2056$

15. Jeffreys R (1975) Clinical and surgical aspects of posterior fossa haemangioblastomata. J Neurol Neurosurg Psychiatry 38: $105-111$

16. Jeffreys R (1975) Pathological and haematological aspects of posterior fossa haemangioblastomata. J Neurol Neurosurg Psychiatry 38:112-119

17. Jellinger $K$, Denk $H$ (1974) Blood group isoantigens in angioblastic meningiomas and hemangioblastomas of the central nervous system. Virchows Arch [A] 364:137-144

18. Jurco S 3rd, Nadji M, Harvey DG, Parker JC Jr, Font RL, Morales AR (1982) Hemangioblastomas: histogenesis of the stromal cell studied by immunohistochemistry. Hum Pathol $13: 13-18$

19. Kato K, Ishiguro Y, Suzuki F, Ito A, Semba R (1982) Distribution of nervous system specific forms of enolase in peripheral tissues. Brain Res 237:441-448

20. Kawamura J, Garcia JH, Kamijyo Y (1973) Cerebellar hemangioblastomas: histogenesis of stromal cells. Cancer $31: 1528-1540$

21. Kepes JJ, Rengachary SS, Lee SH (1979) Astrocytes in the hemangioblastomas of the central nervous system and their 
relationship to stromal cells. Acta Neuropathol (Berl) 47:99-104

22. Lindau A (1926) Studien über Kleinhirncysten: Bau, Pathogenese und Beziehungen zur Angiomatosis Retinae. Acta Pathol Microbiol Scand [Suppl] 1:1-128

23. Lloyd RV, Gikas PW, Chandler WF (1983) Prolactin and growth hormone-producing pituitary adenomas. Am J Surg Pathol 7:21-260

24. McComb RD, Jones TR, Pizzo SV, Ringer DD (1982) Specificity and sensitivity of immunohistochemical detection of Factor VIII/von Willebrand factor antigen in formalin-fixed paraffin-embedded tissue. J Histochem Cytochem 30: 371 377

25. McComb RD, Jones RT, Pizzo SV, Bigner DD (1982) Localization of factor VIII/von Willebrand factor and glial fibrillary acidic protein in the hemangioblastoma: implications for stromal cell histogenesis. Acta Neuropathol (Berl) 56:207-213

26. McGovern VJ, Wyke BD (1948) Hemangioxanthoma of the brain: a study of eight cases of so-called "pseudoxanthomatous" hemangioblastoma. Med J Aust 1:297302

27. Pahlman S, Esscher T, Nilsson K (1986) Expression of $\gamma$ subunit of enolase neuron-specific enolase, in human nonneuroendocrine tumors and derived cell lines. Lab Invest $54: 554-560$

28. Palmer JJ (1972) Haemangioblastomas. Acta Neurochir (Wien) 27:125-148

29. Roussy G, Oberling C (1930) Les tumeurs angiomateuses des centres nerveux. Presse Med 38:179-185

30. Russel DS, Rubinstein LJ (1977) Pathology of tumor of the nervous system, 4th edn. Williams and Wilkins, Baltimore, pp $120-125$
31. Schmechel DE (1985) $\gamma$-Subunit of the glycolytic enzyme enolase: non-specific or neuron-specific? (Editorial). Lab Invest $52: 239-242$

32. Schmechel D, Marangos PJ, Brightman M, Goodwin FK (1978) Brain enolases as specific markers of neuronal and glial cells. Science 199:313-315

33. Schmechel D, Marangos PJ, Brightman M (1978) Neuronspecific enolase is a molecular marker for peripheral and central neuroendocrine cells. Nature 276:834-836

34. Schmechel DE, Brightman MW, Marangos PJ (1980) Neurons switch from non-neuronal enolase to neuronspecific enolase during differentiation. Brain Res 190:195214

35. Spence AM, Rubinstein LJ (1975) Cerebellar capillary hemangioblastoma: its histogenesis studied by organ culture and electron microscopy. Cancer $35: 326-341$

36. Tanimura A, Nakamura $Y$, Hachisuka $H$, Tanimura $Y$, Fukumura A (1984) Hemangioblastoma of the central nervous system: Nature of the stromal cells as studied by the immunoperoxidase technique. Hum Pathol 15:866-869

37. Vinores SA, Bonin JM, Rubinstein LJ, Marangos PJ (1984) Immunohistochemical demonstration of neuron-specific enolase in neoplasms of the CNS and other tissues. Arch Pathol Lab Med 108:536-540

38. Wagner DD, Olmsted JB, Marder VJ (1982) Immunolocalization of von Willebrand protein in WeibelPalade bodies of human endothelial cells. J Cell Biol 95: $355-360$

Received February 17, 1986/Accepted August 7, 1986 